J Am Chem Soc. 2011 March 09; 133(9): 3208-3216. doi:10.1021/ja200089f.

\title{
Total Synthesis of Brevenal
}

\author{
Yuan Zhang, John Rohanna, Jie Zhou, Karthik lyer, and Jon D. Rainier \\ Department of Chemistry, University of Utah, 315 South 1400 East, Salt Lake City, Utah 84112
}

\begin{abstract}
This manuscript describes the total synthesis of the marine ladder toxin brevenal utilizing a convergent synthetic strategy. Critical to the success of this work was the use of olefinic-ester cyclization reactions and the utilization of glycal epoxides as precursors to $\mathrm{C}-\mathrm{C}$ and $\mathrm{C}-\mathrm{H}$ bonds.
\end{abstract}

\section{Graphical abstract}

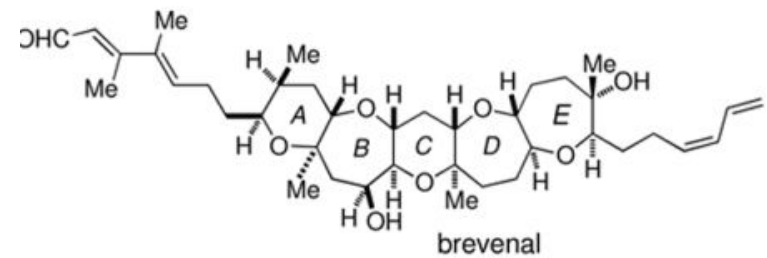

\section{Keywords}

brevenal; ladder toxins; total synthesis; titanium; cyclization; metathesis; epoxide; $C$-glycoside

The dinoflagellate derived marine ladder toxin family of natural products has presented the scientific community with a number of interesting challenges. Structurally, their fused ether architectures remain a challenge in terms of isolation, structure elucidation and synthesis. ${ }^{i}$ Environmentally, their role in food poisoning and red tide events has long made them a curse on marine life and on the fishing industry. ${ }^{\mathrm{ii}}$ Functionally, their ion channel binding properties have made them useful tools in biology. iii Thus, the 2005 report from the Bourdelais and Baden laboratories that described the isolation and structure elucidation of brevenal, a ladder toxin from the dinoflagellate Karenia brevis was met with considerable enthusiasm. ${ }^{\text {iv }}$ In addition to its interesting pentacyclic structure, brevenal's impressive biological profile included ion channel activity, ${ }^{\mathrm{V}}$ a lack of neurotoxicity along with an ability to increase tracheal mucous velocity in animal models of asthma. ${ }^{\mathrm{vi}}$ These properties have led to brevenal receiving a significant amount of attention including from the synthetic community where two total syntheses and one partial synthesis have been reported. ${ }^{\text {vii }}$ The initial total synthesis by the Sasaki group also included a structural reassignment of the $\mathrm{C}(26)$ stereocenter. The synthesis utilized alkyl Suzuki couplings and required 32 steps to the brevenal core, 47 total steps (longest linear sequence) and was completed in $0.2 \%$ overall yield. The second synthesis was accomplished by Kadota and Yamamoto and represented an 
improvement in terms of side-chain construction but not with respect to the number of steps (47 steps to the core, 57 total steps (longest linear sequence), $0.8 \%$ overall yield). Finally, Crimmins recently reported a synthesis of the A,B- and E-rings that centered around his asymmetric glycolate alkylation, RCM chemistry. ${ }^{\text {viii }}$

From a general interest in the synthesis and ion channel binding properties of the ladder toxins, we also became interested in brevenal. ${ }^{\mathrm{ix}, \mathrm{x}}$ Influenced a great deal by methodology that enables the cyclizations of olefins having pendant esters, ${ }^{\text {xi,xii,xiii }}$ we settled upon the strategy illustrated in Scheme 1 that called for the coupling of A-B bicyclic alcohol $\mathbf{4}$ with E-ring acid $\mathbf{5}$ and olefinic-ester cyclization (OLEC) to the brevenal C-ring $2 .{ }^{\text {xiv }}$ Incorporation of the $\mathrm{C}(19)$ angular methyl group and cyclization to the D-ring would complete the brevenal pentacyclic core as $\mathbf{1}$.

With this plan in mind, we initially targeted the generation of the A-B bicycle. As envisioned, the formation of the A-ring required two unprecedented reactions, OLEC to the ring itself where a cyclic template would not be present on the cyclization precursor and a stereoselective epoxidation, $\mathrm{C}-\mathrm{C}$ bond forming reaction on an A-ring dihydropyran that lacked an allylic stereocenter. Our attempts to solve these problems began with 4hydroxybutanal derivative $\mathbf{6}$ and a Brown crotylboration reaction to give $\mathbf{8}$ having the $\mathrm{C}(8)$ and $C(9)$ brevenal stereocenters in $90 \%$ yield and in 95:5 er (Scheme 2). ${ }^{\mathrm{xv}}$ Extension of the olefin and the DCC mediated esterification using acid $\mathbf{1 0}$ gave cyclization precursor 11. In the conversion of olefinic ester 11 into A-ring substrate 12 we compared enol ether-olefin RCM with our recently developed OLEC chemistry and found OLEC to be superior with respect to both yield and efficiency (conditions A and B). The OLEC reaction was run on multi-gram scale and delivered $\mathbf{1 2}$ in $88 \%$ yield. Also interesting was the comparison of the OLEC conditions using $\mathrm{CH}_{3} \mathrm{CHBr}_{2}$ (condition $\mathrm{B}$ ) with those using $\mathrm{CH}_{2} \mathrm{Br}_{2}$ (condition C) and the Tebbe reagent (condition D). ${ }^{\mathrm{x} i, \mathrm{xvii}}$ The use of $\mathrm{CH}_{2} \mathrm{Br}_{2}$ gave a 1:1 mixture of cyclic and acyclic enol ether in $70 \%$ yield while the use of the Tebbe reagent resulted in the decomposition of starting material with no noticeable product formation. ${ }^{\text {xviii }}$

We next examined oxidation to the aforementioned $\mathrm{C}(11)$ hydroxyl group followed by a directed $\mathrm{C}-\mathrm{C}$ bond forming reaction to the $\mathrm{C}(12)$ methyl group. We were pleased to find that the reaction of dihydropyran 12 with DMDO and $\mathrm{AlMe}_{3}$ was stereoselective giving the desired product 16 in $66 \%$ yield (Scheme 3). ${ }^{x i x}$ We envision that the $\mathrm{C}(12)$ angular methyl group comes from a directed transfer of methyl as indicated by $\mathbf{1 5}$.

In light of the fact that we had previously utilized substrates having pendant acetals in the $\mathrm{Me}_{3} \mathrm{Al}$ epoxide opening reactions, ${ }^{\mathrm{xx}}$ the generation of methyl ether $\mathbf{1 7}$ was somewhat surprising to us. While the fact that $\mathbf{1 6}$ and $\mathbf{1 7}$ are readily separable makes this process workable, the generation of $\mathbf{1 7}$ is obviously not ideal. Although we have dedicated a considerable amount of time and effort in attempts to overcome the formation of $\mathbf{1 7}$, to date we have not been able to find conditions or substrates that are more effective than those shown. ${ }^{\mathrm{xxi}}$

Having established the brevenal A-ring, we next targeted the B-ring and subjected $\mathbf{1 6}$ to a two-step cyclization protocol involving the initial generation of a cyclic mixed acetal and the 
subsequent elimination of methanol to give $\mathbf{1 8}$ (Scheme 4). ${ }^{\mathrm{xxii}}$ This sequence was superior to our previously reported one-step reaction using PPTS and pyridine due to the sensitive nature of 18 to PPTS at $130{ }^{\circ} \mathrm{C}$ xxiii DMDO epoxidation and in situ coupling with allyl Grignard gave allyl oxepane $\mathbf{1 9}$ in $87 \%$ yield as a 10:1 mixture of diastereomers. ${ }^{\text {xiv, } x x v}$

The completion of our synthesis of the brevenal A-B ring system is illustrated in Scheme 5. Oxidation of the $\mathrm{C}(15)$ alcohol and Rubottom oxidation introduced the $\mathrm{C}(14)$ hydroxyl group as a 6:1 mixture favoring the desired diastereomer $\mathbf{2 0} .{ }^{\mathrm{xxvi}}$ In a similar fashion to Sasaki's findings with a related substrate, ${ }^{\text {via }}$ the $i-\mathrm{Bu}_{2} \mathrm{AlH}$ reduction of $\mathbf{2 0}$ delivered the $\mathrm{C}(14), \mathrm{C}(15)$ diol corresponding to $\mathbf{2 1}$ as the major product. It turns out that a free alcohol is required for the synthesis of $\mathbf{2 1}$. When a C(14) TES ether was used in the reduction, the undesired $\mathrm{C}(15)$ stereoisomer was isolated as the major product. Treatment of the diol with $\mathrm{Bu}_{2} \mathrm{SnO}$ and benzyl bromide gave $\mathrm{A}, \mathrm{B}$ coupling precursor $\mathbf{2 1}$ as the major product. ${ }^{\mathrm{xxvii}}$ Worthy of mention here is that all of the stereocenters in $\mathbf{2 1}$ arose from substrate controlled diastereoselective reactions once the $\mathrm{C}(8)$ and $\mathrm{C}(9)$ stereocenters had been established (Scheme 2).

With 21 in hand, we next targeted the synthesis of the brevenal E-ring (Scheme 6). From olefinic-ester 22, which is available in 4 steps from L-glyceraldehyde acetonide, ${ }^{\text {xxviii }}$ OLEC successfully gave oxepene $\mathbf{2 3}$ in $66 \%$ yield along with $22 \%$ of the corresponding acyclic enol ether. The acyclic enol ether by-product could be converted into $\mathbf{2 3}$ using the Grubbs $2^{\text {nd }}$ generation catalyst $\mathbf{1 3}$ but the conversion was relatively low, i.e. $35 \%$, and included varying quantities of the corresponding dihydropyran from olefin isomerization and cyclization. ${ }^{\text {xxix }}$ Oxidation of $\mathbf{2 3}$ and in situ reduction using $i-\mathrm{Bu}_{2} \mathrm{AlH}$ gave $\mathbf{2 4}$ as a single diastereomer. ${ }^{\mathrm{xx}}$ Mechanistically, we believe that the epoxide oxygen atom directs the reduction in a similar fashion to the analogous reaction with $\mathrm{Me}_{3} \mathrm{Al}$, e.g. 15, Scheme 3. ${ }^{\mathrm{xix}}$ Oxidation of the $\mathrm{C}(26)$ alcohol to the corresponding ketone and addition of $\mathrm{MeMgBr}$ in toluene gave a 7:1 mixture of $3^{\circ}$ alcohol 25 . $^{\text {vii,xxxi }}$ Silyl ether formation, hydrolysis of the benzylidene acetal, and conversion of the $\mathrm{C}(21)$ alcohol into the corresponding homoallyl derivative gave 27. ${ }^{\mathrm{xx} x i i}$ After switching the $\mathrm{C}(23)$ protecting group from TES to PMB, oxidative fragmentation of the alkene afforded the E-ring coupling precursor 29.

With the synthesis of both of the precursors completed we were prepared to examine their utility in the generation of the remainder of brevenal. Esterification of E-ring acid $\mathbf{2 9}$ using A,B-alcohol 21 and the Yamaguchi acid chloride gave ester $\mathbf{3 0}$ (Scheme 7). ${ }^{x x x i i i}$ In spite of the presence of a number of potential coordination sites, the Ti OLEC chemistry was impressive here giving $\mathrm{C}$-ring enol ether $\mathbf{3 1}$ in $83 \%$ yield.

Our initial attempts to incorporate the $\mathrm{C}(19)$ angular methyl group are outlined in Schemes 8 and 9. From 31, our initial plan was to utilize the oxidation, $\mathrm{AlMe}_{3}$ protocol. Based on a related reaction that had been successful in our hemibrevetoxin B synthesis we had hoped that the $\mathrm{C}(14)$ ether would control the facial selectivity in the epoxidation reaction and as a consequence of the mechanism (see Scheme 3), the stereoselective incorporation of the $\mathrm{C}(19)$ angular methyl group. In the event, exposure of a $\mathrm{CH}_{2} \mathrm{Cl}_{2}$ solution of the epoxide from 31 to $\mathrm{AlMe}_{3}$ resulted in the generation of ketone 33. Presumably 33 comes from a pinacol-type rearrangement of the intermediate epoxide, i.e. 32. ${ }^{\text {xxiv }}$ 
The choice of solvent proved important in overcoming the generation of 33. When the epoxide opening reaction was carried out in toluene rather than $\mathrm{CH}_{2} \mathrm{Cl}_{2}$ we isolated 34 having the desired connectivity but as a mixture of $\mathrm{C}(18)$ and $\mathrm{C}(19)$ diastereomers (Scheme 9). ${ }^{\mathrm{Xxxv}}$ While the observed solvent effect is certainly interesting, that $\mathbf{3 4}$ was isolated as an inseparable mixture of diastereomers as a result of the poor selectivity in the epoxidation reaction made this approach untenable and forced us to modify our strategy.

In spite of the disappointing result to $\mathbf{3 4}$, we felt that the facility of both epoxide and oxocarbenium ion formation was advantageous. To overcome the lack of selectivity in the $\mathrm{C}-\mathrm{C}$ bond forming reaction, we set out to identify conditions where the stereochemical outcome of the $\mathrm{C}(19) \mathrm{C}-\mathrm{C}$ bond formation would be decoupled from the stereochemistry of the $\mathrm{C}(18), \mathrm{C}(19)$ epoxide. That is, we felt that if we were able to generate an oxocarbenium ion that was analogous to $\mathbf{3 3}$ but that had the adjacent alkoxide masked with a nontransferable group, the lack of selectivity in the $\mathrm{C}(19)$ bond formation might be overcome. Largely driving these efforts was the overwhelming propensity for axial addition to oxocarbenium ions in six-membered rings. ${ }^{x x x v i}$ Although precedent for the proposed reaction sequence existed, ${ }^{\mathrm{xxxvii}}$ to the best of our knowledge the precedent was not extensive. Thus, before carrying out the chemistry on our brevenal substrate we opted to initially explore the proposed chemistry with model bicyclic enol ether $\mathbf{3 5}$. Enol ether $\mathbf{3 5}$ was chosen largely because we had previously demonstrated that its DMDO epoxidation chemistry was not selective. ${ }^{\mathrm{xxv}}$ In the event, when the epoxide from $\mathbf{3 5}$ was exposed to a mixture of TESOTf and $\mathrm{ZnMe}_{2}{ }^{\mathrm{xxx} x i i i}$ we isolated $C, C$-ketal $\mathbf{3 8}$ having the expected mixture of silyl ether diastereomers but as a single stereoisomer at the newly formed $3^{\circ}$ ether center (Scheme 10). Through the use of nOe correlation experiments, we subsequently showed that the methyl group was in the desired axial position.

Having established the ability to generate oxocarbenium ions in the model substrate, we were prepared to examine the reaction in brevenal substrate $\mathbf{3 1}$ (Scheme 11). Unfortunately the treatment of the epoxide from $\mathbf{3 1}$ with TESOTf and $\mathrm{ZnMe}_{2}$ was capricious giving trace amounts of the desired product $\mathbf{4 0}$ along with other oxidized material that included methanol adduct 39. As has been proposed by Wei for a related transformation, we believe that $\mathbf{3 9}$ comes from the oxidation of $\mathrm{ZnMe}_{2}$ by the epoxide from $\mathbf{3 1}$ and the subsequent transfer of methoxide to the epoxide. ${ }^{\mathrm{xx} x \mathrm{x}}$

Having failed to directly introduce the $\mathrm{C}(19)$ angular methyl group into 31, we decided to examine a stepwise solution to the problem. In contrast to the results from the reaction of $\mathrm{ZnMe}_{2}$, the addition of EtSH to the epoxide from $\mathbf{3 1}$ worked well giving a mixture of $\mathrm{C}(18)$ alcohol diastereomers $\mathbf{4 1}$ in 89\% yield (Scheme 12). ${ }^{\mathrm{xl}}$ The stereoselective introduction of the C(19) methyl group was finally accomplished by subjecting the TES ether analog of $\mathbf{4 1}$ to Kadota's recently reported conditions, $\mathrm{Me}_{2} \mathrm{Zn}$ and $\mathrm{Zn}(\mathrm{OTf})_{2}$, to give $42 .{ }^{x l i}$ Removal of the TES group and oxidation gave ketone $\mathbf{4 3}$ as a single diastereomer in $81 \%$ yield for the five steps following oxidative removal of the PMB ether. A harbinger of future problems with the reductive cyclization of $\mathbf{4 3}$ was that it existed exclusively (by ${ }^{1} \mathrm{H}$ NMR) as the hydroxy ketone tautomer and not as the corresponding hemiketal. 
As mentioned above, the generation of the brevenal D-ring from $\mathbf{4 3}$ required a reductive cyclization reaction. To this goal, attempts to convert $\mathbf{4 3}$ directly into 45 using TMSOTf and $\mathrm{Et}_{3} \mathrm{SiH}$ resulted in decomposition with no discernable product formation (Scheme 13). ${ }^{x}$ lii A more conservative approach involving the generation of mixed ketal $\mathbf{4 4}$ was more successful but still required the initial conversion of the ketone into the corresponding dithioketal followed by a $\mathrm{AgClO}_{4}$ catalyzed cyclization to give 44 . ${ }^{\text {xliii }}$ Unfortunately, attempts to reduce the thioketal or the corresponding sulfone using either homolytic or heterolytic reaction conditions failed miserably. These reactions led to either the recovery of $\mathbf{4 4}$ or to its conversion into intractable mixtures. From all of these studies it became clear that the presence of the $\mathrm{C}(19)$ angular methyl group was significantly inhibiting our efforts to the brevenal C-ring.

We also examined the reductive cyclization of ketone $\mathbf{4 6}$ where the reduction would take place at the D,E-ring junction and $\mathrm{C}(23){ }^{x}{ }^{\text {xiv }}$ In contrast to the related reaction with $\mathbf{4 4}$, the homolytic reduction of thioketal $\mathbf{4 7}$, while sluggish, was successful resulting in oxepane $\mathbf{4 8}$ as a single diastereomer (Scheme 14). Removal of the benzyl groups and conversion of the resulting alcohols into the corresponding TBS ethers gave pentacycle 49, a compound that had been reported previously by Sasaki during his brevenal work. ${ }^{\text {vii }}$ Unfortunately our spectroscopic data for $\mathbf{4 9}$ did not match that previously reported. While not definitively established, we presume that pentacycle $\mathbf{4 9}$ differs from the brevenal core at $\mathrm{C}(23)$.

The effectiveness of the OLEC approach to the ladder toxins is at least partly due to the fact that the coupling involves an esterification reaction and, as a result, the ease with which coupling partners can be swapped out. Thus, while our lack of success in converting C-ring precursors 43 and 46 into the brevenal core was disappointing, we realized that we could easily modify the strategy by coupling an A,B-acid with an E-ring alcohol as represented by the coupling of $\mathbf{5 3}$ with $\mathbf{5 4}$ to give $\mathbf{5 2}$ (Scheme Obviously, this new strategy required OLEC to the D-ring oxepene, i.e. $\mathbf{5 1 .}$

While OLEC to the D-ring would certainly be more challenging than the analogous reaction to the C-ring other aspects of the new strategy were considered to be advantageous. Namely, the late stage introduction of the $\mathrm{C}(19)$ angular methyl group and the late stage acid mediated cyclization to the C-ring would help us to overcome some of the more problematic transformations in our previous efforts.

With the preceding line of thought as background we utilized Shiina's esterification conditions and anhydride $\mathbf{5 7}$ to couple olefinic-alcohol $\mathbf{5 6}$ with acid $\mathbf{5 5}$ to give $\mathbf{5 8}$ (Scheme 16). ${ }^{x l v}$ Yamaguchi conditions were not as effective here. After optimization of the cyclization conditions we were pleased to be able to generate oxepene $\mathbf{5 9}$ in $30 \%$ yield from the OLEC reaction of $\mathbf{5 8}$. Acyclic enol ether $\mathbf{6 0}$ was the major product here and we were pleased to find that it could be recycled using the Grubbs $2^{\text {nd }}$ generation catalyst, i.e. $\mathbf{1 3}$ (Scheme 2), and ethylene at elevated temperatures. This gave an additional 35\% of cyclic material that consisted of a 5:1 mixture of $\mathbf{5 9}$ and the corresponding dihydropyran (65\% overall yield of 59). ${ }^{x l v i}$ Because they proved to be important, the OLEC cyclization conditions are worthy of mentioning here. As currently employed, these reactions require the generation of $\mathrm{Ti}(\mathrm{III})$ prior to the addition of substrate and $\mathrm{CH}_{3} \mathrm{CHBr}_{2}{ }^{\text {xlvii }}$ Interestingly, 
when dibromoethane and $\mathbf{5 8}$ were added to the reduced Ti reagent at rt and subsequently slowly warmed to reflux over 15 minutes, only acyclic enol ether was observed. When dibromoethane and $\mathbf{5 8}$ were added to reagent at $\mathrm{rt}$ and warmed to reflux over two minutes a $30 \%$ yield of $\mathbf{5 9}$ was isolated. While we do not understand the importance of the temperature on the reaction, it appears to point to the presence of multiple Ti species and their differential reactivity with $\mathbf{5 8}$.

With the D-ring in hand we targeted the generation of the C-ring. To this goal, the oxidationreduction reaction of $\mathbf{5 9}$ gave ketone $\mathbf{6 1}$ in $65 \%$ overall yield following oxidation of the $2^{\circ}$ alcohol (Scheme 17). In contrast to the oxidation of 31 (Scheme 9), the DMDO oxidation of 59 gave the corresponding epoxide as a single diastereomer. Based on DFT calculations in a model oxepene, we believe that the high diastereoselectivity in the generation of the $\mathrm{C}(18)$ stereocenter is a result of unfavorable torsional interactions between the $\mathrm{C}(20)$ pseudo-axial hydrogen atom and DMDO during the transition state that would lead to the $\mathrm{C}(18)$ epimer of 61. ${ }^{\text {xlviii }}$ The synthesis of $\mathbf{6 1}$ intercepts the same intermediate in Sasaki's synthesis of brevenal. In contrast to pentacycle $\mathbf{5 4}$, the spectral data $\left({ }^{1} \mathrm{H},{ }^{13} \mathrm{C}, \mathrm{IR}, \mathrm{MS},[\mathrm{a}]_{\mathrm{D}}{ }^{20}\right)$ matched that reported previously. vii

Having succeeded in synthesizing $\mathbf{6 1}$, we were finally prepared to complete the synthesis of the $\mathrm{C}$-ring and thus the brevenal pentacyclic core. In contrast to our attempts with $\mathbf{4 8}$, the cyclization of $\mathbf{6 1}$ to give the C-ring was uneventful. Impressively, when $\mathbf{6 1}$ was subjected to $\mathrm{Zn}(\mathrm{OTf})_{2}$ and EtSH we were able to remove both TES groups and effect cyclization to generate the desired $\mathrm{C}(19)$ thioketal $\mathbf{6 2}$ after the generation of the C(14) TBS ether.

The completion of the brevenal core required the incorporation of the $\mathrm{C}(19)$ angular methyl group. This task was accomplished using the Kadota methodology and resulted in the brevenal core structure as $\mathbf{6 3}$ in 94\% yield (Scheme 18).

Our total synthesis of brevenal was completed using a modification of Yamamoto and Kadota's end game protocol for the incorporation of the side chains. viic These efforts began with the E-ring side chain ('Scheme 19). Yamamoto and Kadota had utilized hydrogenolysis to remove the $\mathrm{C}(30)$ benzyl ether. In our hands, reductive conditions were higher yielding giving the corresponding $1^{\circ}$ alcohol. Parikh-Doering oxidation and Wittig coupling using phosphonium salt 64 gave the corresponding $Z$-alkene and 65 following oxidative elimination of the phenyl selenide. ${ }^{x \text { lix }}$ As has been reported previously, ${ }^{1}$ the selective removal of the $1^{\circ}$ TBDPS group in the presence of the $2^{\circ}$ and $3^{\circ}$ TBS groups was accomplished using buffered TBAF. Oxidation of the resulting $1^{\circ}$ alcohol and HornerEmmons reaction with the lithium salt of phosphonate $\mathbf{6 6}$ gave $\mathbf{6 7}$ in $85 \%$ yield for the two steps. Completion of brevenal was accomplished through HF•pyridine removal of the TBS ethers, $i-\mathrm{Bu}_{2} \mathrm{AlH}$ reduction of the ester and selective oxidation of the resulting allylic alcohol. Yamamoto and Kadota had carried out the reduction of the ester prior to the removal of the TBS groups using TBAF. In our hands the allylic alcohol reduction product was unstable to the chromatography that was required after the TBAF deprotection step. Our spectral data for brevenal matched that reported previously. 
In conclusion, we have carried out the total synthesis of brevenal utilizing OLEC chemistry to both build the A,B- and E-rings and to carry out their convergent coupling. From our perspective, our synthesis compares favorably with other efforts towards this molecule: it required 28 steps to the core from 1,4-butanediol and 38 steps to brevenal (longest linear sequence, $0.99 \%$ overall yield). The synthesis has not only enabled us to further explore and optimize the OLEC reactions but it has also led to a better understanding of the use of glycal epoxides in a complex setting. We believe that this work will lead to a better understanding of brevenal's impressive biological properties including its ion channel activity. These latter studies will be reported in due course.

\section{Supplementary Material}

Refer to Web version on PubMed Central for supplementary material.

\section{Acknowledgments}

We are grateful to the National Institutes of Health for support of this work (GM56677). The authors would like to thank the support staff at the University of Utah and especially Dr. Dennis Edwards (NMR) and Dr. Jim Muller (mass spectrometry) for help in obtaining data. The authors would also like to thank Dr. Henry W. B. Johnson for carrying out preliminary studies.

\section{REFERENCES CITED}

i. For Reviews On The Synthesis Of Ladder Toxins See:(a) Isobe M, Hamajima A. Nat Prod Rep. 2010; 27:1204-1226. [PubMed: 20589300] (b) Nicolaou KC, Frederick MO, Aversa RJ. Angew Chem Int Ed. 2008; 47:7182-7225.(c) Sasaki M, Fuwa H. Nat Prod Rep. 2008; 25:401-426. [PubMed: 18389143] (d) Nakata T. Chem Rev. 2005; 105:4314-4347. [PubMed: 16351046] (e) Marmsater FP, West FG. Chem Eur J. 2002; 8:4346-4353. [PubMed: 12355522]

ii. For reviews on the impact of red tides ciguatera on the environment human health, see(a) Landsberg JH, Flewelling LJ, Naar J. Harmful Algae. 2009; 8:598-607.(b) Lewis RJ. Toxicon. 2006; 48:799-809. [PubMed: 16930661]

iii. For representative studies of the ion channel binding of ladder toxins, see:(a) Trainer VL, Thomsen WJ, Catterall WA, Baden DG. Mol Pharmacol. 1991; 40:988-994. [PubMed: 1661842] (b) Gawley RE, Rein KS, Kinoshita M, Baden DG. Toxicon. 1992; 30:780-785. [PubMed: 1324537] (c) Jeglitch G, Rein K, Baden DG, Adams DJ. J Pharmacol Exp Therap. 1998; 284:516-525. [PubMed: 9454792] (d) Kopljar I, Labro AJ, Cuypers E, Johnson HWB, Rainier JD, Tytgat J, Snyders DJ. Proc Nat Acad Sci. 2009; 106:9896-9901. [PubMed: 19482941]

iv. Bourdelais AJ, Jacocks HM, Wright JLC, Bigwarfe PM Jr, Baden DG. J Nat Prod. 2005; 68:2-6. [PubMed: 15679307]

v. (a) Bourdelais AJ, Campbell S, Jacocks H, Naar J, Wright JLC, Carsi J, Baden DG. Cell Mol Neurobio. 2004; 24:553-563.(b) LePage KT, Rainier JD, Johnson HWB, Baden DG, Murray TF. J Pharmacol Exp Therap. 2007; 323:174-179. [PubMed: 17609421] (c) Cesar M, Wen PJ, Nguyen-Huu TD, Alvarez M, Benoit E, Bourdelais AJ, Lewis RJ, Baden DG, Molgo J, Meunier FA. PloS one. 2008; 3:e3448. [PubMed: 18941627] (d) Errera RM, Bourdelais A, Drennan MA, Dodd EB, Henrichs DW, Campbell L. Toxicon. 2010; 55:195-203. [PubMed: 19631681]

vi. (a) Abraham WM, Bourdlais AJ, Sabater JR, Ahmed A, Lee TA, Serebriakov I, Baden DG. Am J Resp Crit Care Med. 2005; 171:26-34. [PubMed: 15447946] (b) Potera C. Science. 2007; 316:1561-1562. [PubMed: 17569840]

vii. (a) Fuwa H, Ebine M, Bourdelais AJ, Baden DG, Sasaki M. J Am Chem Soc. 2006; 128:16989_ 16999. [PubMed: 17177450] (b) Ebine M, Fuwa H, Sasaki M. Org Lett. 2008; 10:2275-2278. [PubMed: 18444658] (c) Takamura H, Kukuchi S, Nakamura Y, Yamagami Y, Kishi T, Kadota I, Yamamoto Y. Org Lett. 2009; 11:2531-2534. [PubMed: 19441795]

viii. Crimmins MT, Shamszad M, Mattson AE. Org Lett. 2010; 12:2614-2617. [PubMed: 20446718] 
ix. See reference ${ }^{3 d}$ and(a) Cuypers E, Abdel-Mottaleb Y, Rainier JD, Tytgat J. Toxicon. 2008; 51:974-983. [PubMed: 18313714] (b) Cao Z, George J, Gerwick WH, Baden DG, Rainier JD, Murray TF. J Pharm Exp Therap. 2007; 326:604-613.(c) Cuypers E, Yanagihara A, Rainier JD, Tytgat J. Biochem Biophys Res Commun. 2007; 361:214-217. [PubMed: 17659256] (d) LePage KT, Rainier JD, Johnson HWB, Baden DG, Murray TF. J Pharm Exp Therap. 2007; 323:174179.

x. (a) Johnson HWB, Majumder U, Rainier JD. Chem Eur J. 2006; 12:1747-1753. [PubMed: 16331719] (b) Johnson HWB, Majumder U, Rainier JD. J Am Chem Soc. 2005; 127:848-849. [PubMed: 15656618] (c) Rainier JD, Allwein SP, Cox JM. J Org Chem. 2001; 66:1380-1386. [PubMed: 11312970]

xi. (a) Takai K, Kakiuchi T, Kataoka Y, Utimoto K. J Org Chem. 1994; 59:2668-2670.(b) Clark JS, Kettle JG. Tetrahedron Lett. 1997; 38:127-130.(c) Rainier JD, Allwein SP. J Org Chem. 1998; 63:5310-5311.

xii. Rainier JD, Cox JM, Allwein SP. Tetrahedron Lett. 2001; 42:179-181.

xiii. (a) Iyer K, Rainier JD. J Am Chem Soc. 2007; 129:12604-12605. [PubMed: 17900112] (b) Majumder U, Rainier JD. Tetrahedron Lett. 2005; 46:7209-7211.

xiv. We employed a related strategy in our synthesis of gambierol. See references ${ }^{10 \mathrm{a}}$ and $10 \mathrm{~b}$.

xv. Brown HC, Bhat KS. J Am Chem Soc. 1986; 108:293-294.(b) Statsuk AV, Liu D, Kozmin SA. J Am Chem Soc. 2004; 126:9546-9547. [PubMed: 15291551]

xvi. Nicolaou showed that the Tebbe reagent performs OLEC reactions via an enol ether-olefin RCM reaction. See reference ${ }^{17}$.

xvii. (a) Nicolaou KC, Postema MHD, Claiborne CF. J Am Chem Soc. 1996; 118:1565-1566.(b) Nicolaou KC, Postema MHD, Yue EW, Nadin A. J Am Chem Soc. 1996; 118:10335-10336.

xviii. Nicolaou recently used our reduced Ti strategy to generate one of the maitotoxin subunits.Nicolaou KC, Gelin CF, Seo JH, Huang Z, Umezawa T. J Am Chem Soc. 2010; 132:9900-9907. See. [PubMed: 20666400]

xix. Rainier JD, Cox JM. Org Lett. 2000; 2:2707-2709. [PubMed: 10990433]

xx. See reference ${ }^{10 \mathrm{c}}$ andRainier JD, Allwein SP, Cox JM. Org Lett. 2000; 2:231-234. [PubMed: 10814289]

xxi. Conditions that were examined included the use of other solvents (THF and hexanes), temperature profiles (lower and higher and rates of heating), rates of addition of $\mathrm{Me}_{3} \mathrm{Al}$ and nucleophiles $\left(\mathrm{ZnMe}_{2}, \mathrm{MeMgBr}\right)$. Alternate substrates have included the use of TBS ethers, benzyl ethers, and cyclic acetals instead of the dimethyl acetal in $\mathbf{1 4}$.

xxii. Tsunoda T, Suzuki M, Noyori R. Tetrahedron Lett. 1980; 21:1357-1358.

xxiii. Rainier JD, Allwein SP. Tetrahedron Lett. 1998; 39:9601-9604.

xxiv. We believe that the facial selectivity in the epoxidation of $\mathbf{1 8}$ is dictated by the $\mathrm{C}(12)$ angular methyl group and that the $\mathrm{C}(16)$ stereochemistry comes from the direct opening of the epoxide with allyl magnesium bromide. See reference ${ }^{25}$.

xxv. Allwein SP, Cox JM, Howard BE, Johnson HWB, Rainier JD. Tetrahedron. 2002; 58:1997-2009.

xxvi. Rubottom GM, Vazquez MA, Pelegrina DR. Tetrahedron Lett. 1974; 49:4319-4322.

xxvii. Kadota I, Yamamoto Y. J Org Chem. 1998; 63:6597-6606.

xxviii. See reference ${ }^{34}$.

xxix. The use of additives to overcome olefin isomerization have largely been unsuccessful in our hands. For examples of the successful inhibition of olefin isomerization during RCM seeHong SH, Sanders DP, Lee CW, Grubbs RH. J Am Chem Soc. 2005; 127:17160-17161. [PubMed: 16332044]

xxx. Majumder U, Cox JM, Johnson HWB, Rainier JD. Chem Eur J. 2006; 12:1736-1746. [PubMed: 16331718]

xxxi. Feng F, Murai A. Chem Lett. 1992:1587-1590.

xxxii. (a) Kotsuki H, Kadota I, Ochi M. Tetrahedron Lett. 1989; 30:3999-4000.(b) Kotsuki H, Kadota I, Ochi M. J Org Chem. 1990; 55:4417-4422.

xxxiii. Inanaga J, Hirata K, Saeki H, Tsutomu K, Yamaguchi M. Bull Chem Soc Jpn. 1979; 52:1989_ 1993. 
xxxiv. Osei Akoto C, Rainier JD. Angew Chem Int Ed. 2008; 47:8055-8058.

$\mathrm{xxxv}$. We speculate that the role of toluene is to stabilize the oxocarbenium intermediate through $\pi$ stacking interactions.

xxxvi. Deslongchamps, P. Stereoelectronic Effects in Organic Chemistry. Pergamon; New York: 1983. p. 209-221.

xxxvii. Roberts SW, Rainier JD. Org Lett. 2005; 7:1141-1144. [PubMed: 15760159]

xxxviii. Zinc reagents have been added previously to glycal epoxides but not in the presence of silyl triflates.(a) Cheng G, Fan R, Hernandez-Torres JM, Boulineaqu FP, Wei A. Org Lett. 2007; 9:4849-4852. See. [PubMed: 17929936] (b) Xue S, Han K, He L, Guo Q. Synlett. 2003; 6:870872.

xxxix. Wei has reported a similar phenomenon. See reference ${ }^{38 a}$. xl. See references ${ }^{7 a}$ and ${ }^{8}$.

xli. Kadota I, Kishi T, Fujisawa Y, Yamagami Y, Takamura H. Tetrahedron Lett. 2010; 51:3960-3961. xlii. (a) Oishi T, Imaizumi T, Murata M. Chem Lett. 2010; 39:108-109.(b) Torikai K, Watanabe K, Minato H, Imaizumi T, Murata M, Oishi T. Synlett. 2008:2368-2372.(c) Evans PA, Cui J, Gharpure SJ. Org Lett. 2003; 5:3883-3885. [PubMed: 14535734] (d) Evans PA, Cui J, Gharpure SJ, Hinkle RJ. J Am Chem Soc. 2003; 125:11456-11457. [PubMed: 13129322]

xliii. Nicolaou KC, Prasad CVC, Hwang C-K, Duggan ME, Veale CA. J Am Chem Soc. 1989; 111:5321-5330.

xliv. Ketone $\mathbf{4 6}$ was prepared in six steps from $\mathbf{4 2 .}$

xlv. Shiina I, Kubota M, Ibuka R. Tetrahedron Lett. 2002; 43:7535-7539.

xlvi. Schmidt B. J Mol Cat A: Chem. 2006; 254:53-57.

xlvii. Oshiki T, Kiriyama T, Tsuchida K, Takai K. Chem Lett. 2000:334-335.

xlviii. Orendt AM, Roberts SW, Rainier JD. J Org Chem. 2006; 71:5565-5573. [PubMed: 16839135]

xlix. Nicolaou KC, Reddy KR, Skokotas G, Sato F, Xiao XY. J Am Chem Soc. 1992; 114:7935-7936. (b) Nicolaou KC, Reddy KR, Skokotas G, Sato F, Xiao XY, Hwang CK. J Am Chem Soc. 1993; 115:7558-3575.

1. Higashibayashi S, Shinko K, Ishizu T, Hashimoto K, Shirahama H, Nakata M. Synlett. 2000:13061308. 

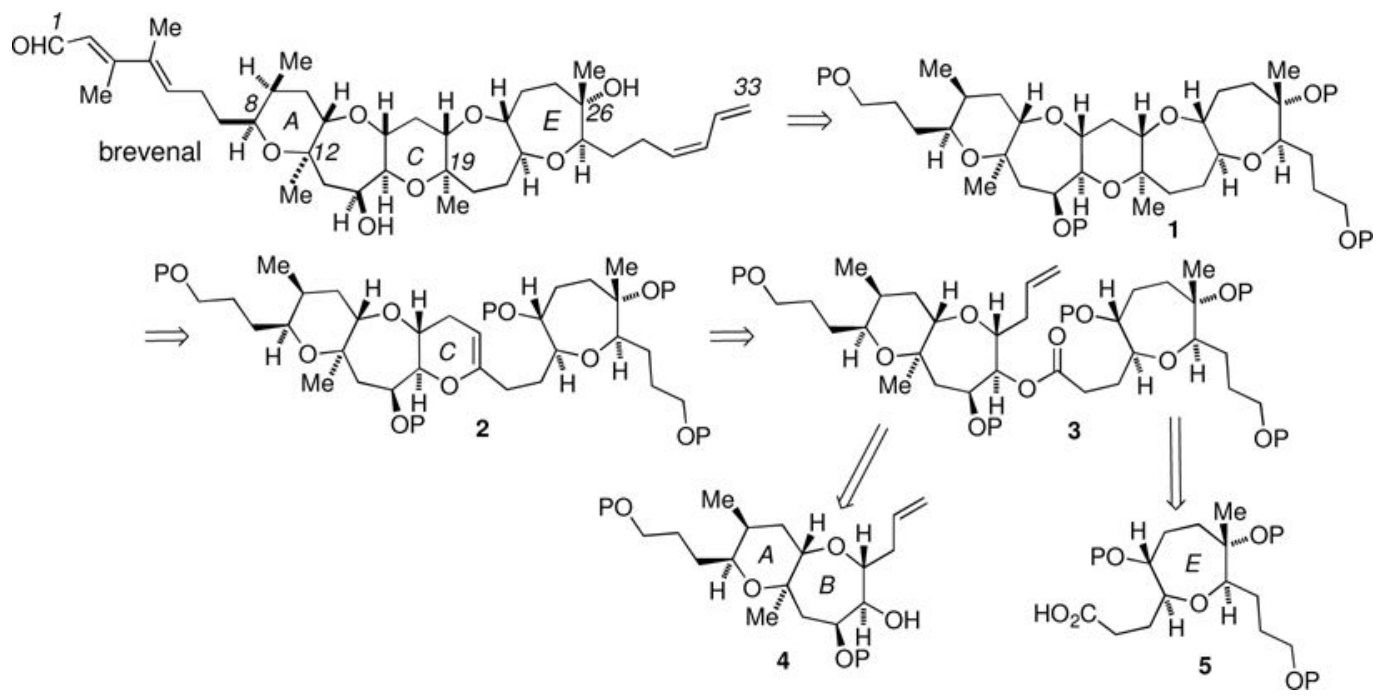

Scheme 1.

OLEC Plan to Brevenal 

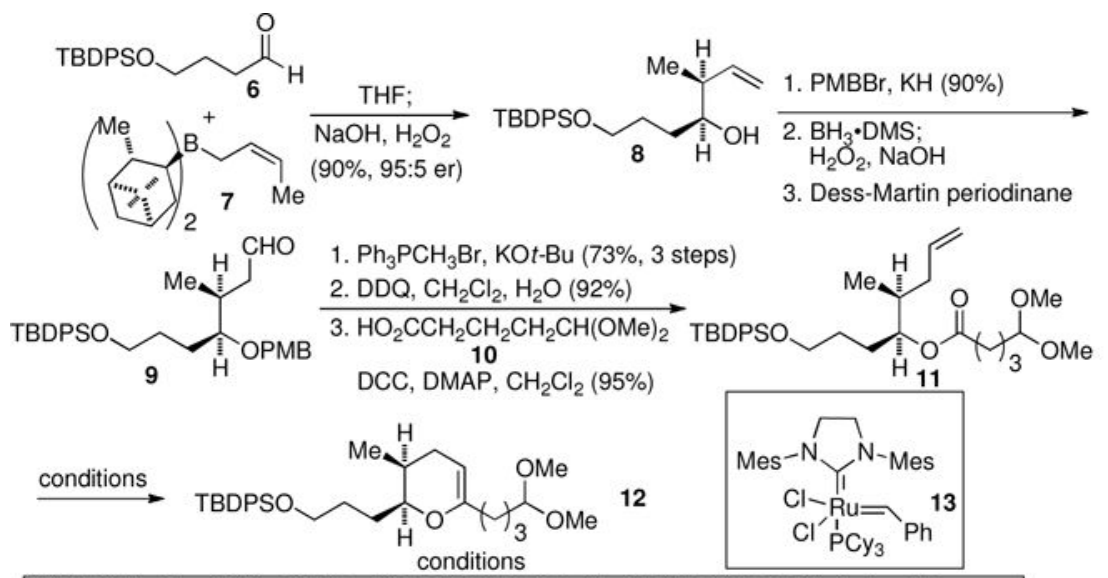

(A) (1) $\mathrm{TiCl}_{4}, \mathrm{Zn}, \mathrm{PbCl}_{2}, \mathrm{CH}_{2} \mathrm{Br}_{2}$, THF, TMEDA, $\mathrm{CH}_{2} \mathrm{Cl}_{2}, 65{ }^{\circ} \mathrm{C}$ (2) 13 (75\%, 2 steps) ${ }^{a}$

(B) $\mathrm{TiCl}_{4}, \mathrm{Zn}, \mathrm{PbCl}_{2}, \mathrm{CH}_{3} \mathrm{CHBr}_{2}$, THF, TMEDA, $\mathrm{CH}_{2} \mathrm{Cl}_{2}, 65{ }^{\circ} \mathrm{C}(88 \%)$

(C) $\mathrm{TiCl}_{4}, \mathrm{Zn}, \mathrm{PbCl}_{2}, \mathrm{CH}_{2} \mathrm{Br}_{2}, \mathrm{THF}, \mathrm{TMEDA}, \mathrm{CH}_{2} \mathrm{Cl}_{2}, 65^{\circ} \mathrm{C}(70 \%, 1: 1 \text { mixture acyclic: cyclic) })^{a}$ (D) $\mathrm{Cp}_{2} \mathrm{TiCl}_{2}, \mathrm{AlMe}_{3}$ (decomposition)

${ }^{a}$ we believe that the lower yield in entry $\mathrm{C}$ is due to the instability of the acyclic enol ether to purification

Scheme 2.

Brevenal A-Ring 

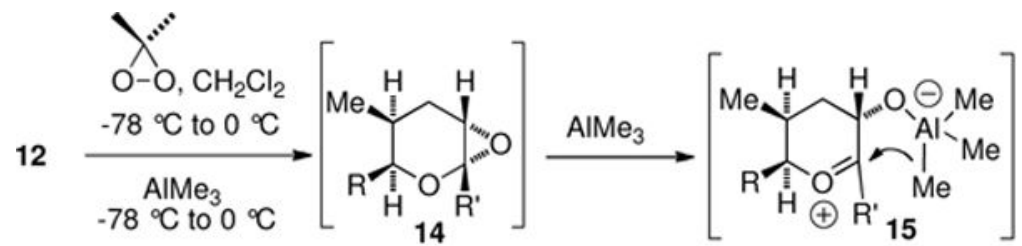

\section{$\mathrm{R}=\mathrm{CH}_{2} \mathrm{CH}_{2} \mathrm{CH}_{2} \mathrm{OTBDPS}$}

$\mathrm{R}^{\prime}=\mathrm{CH}_{2} \mathrm{CH}_{2} \mathrm{CH}_{2} \mathrm{CH}(\mathrm{OMe})_{2}$

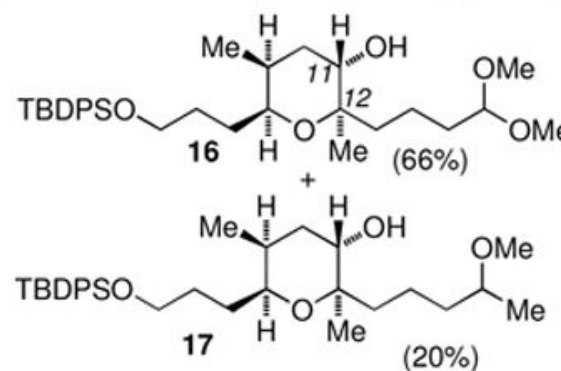

Scheme 3.

Epoxidation-Directed Addition to the A-Ring 

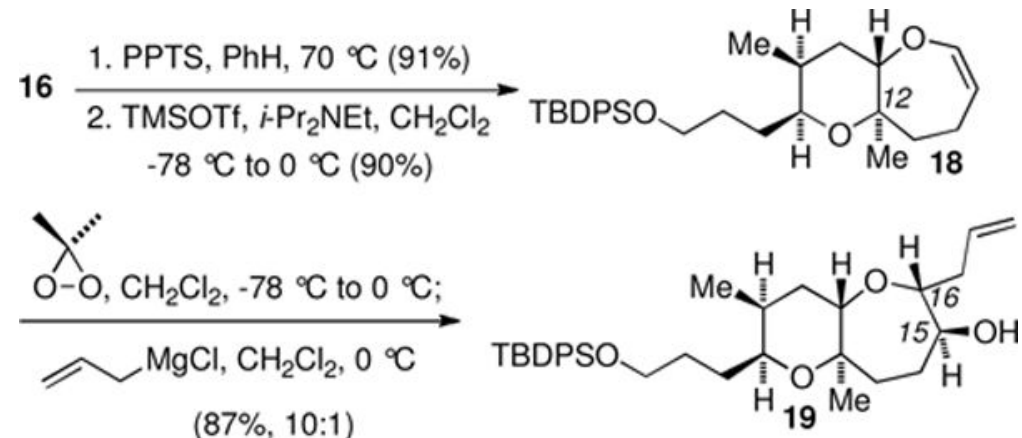

Scheme 4.

Brevenal's B-Ring 

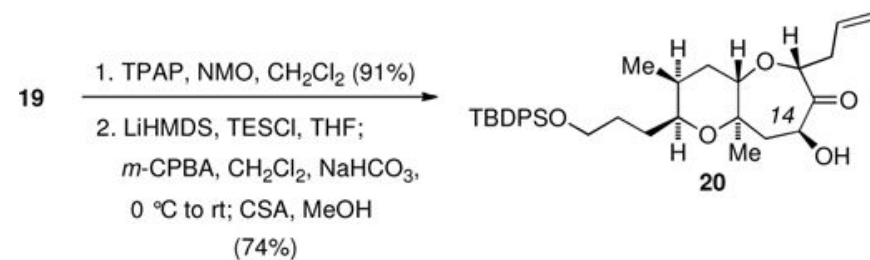

20

$(74 \%)$

Scheme 5.

Completion of Brevenal's A-B Ring Precursor
1. $i-\mathrm{Bu}_{2} \mathrm{AlH}, \mathrm{THF},-78{ }^{\circ} \mathrm{C}$

2. $\mathrm{Bu}_{2} \mathrm{SnO}, \mathrm{MeOH}, 70{ }^{\circ} \mathrm{C}$; $\mathrm{BnBr}, \mathrm{DMF}, \mathrm{CsF}$, $\mathrm{rt}$

(82\%, 6:1 regioselectivity)

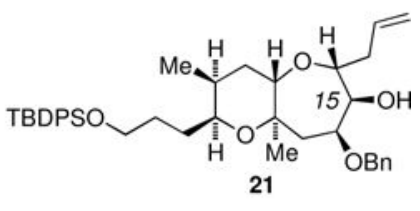

21 


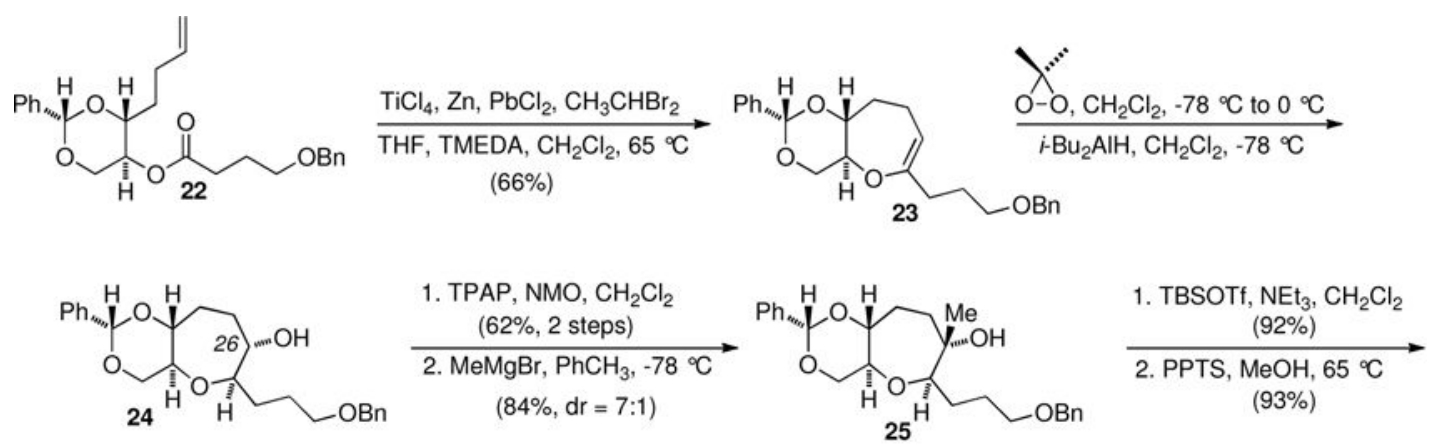

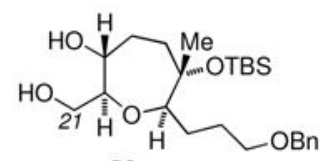

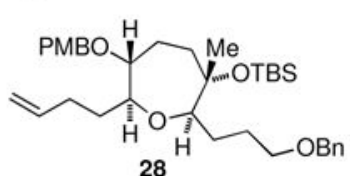

1. $\mathrm{Tf}_{2} \mathrm{O}, 2,6$-lutidine, $\mathrm{CH}_{2} \mathrm{Cl}_{2}$;

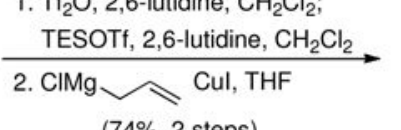

(74\%, 2 steps)

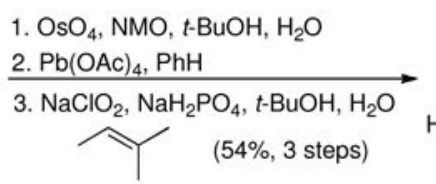

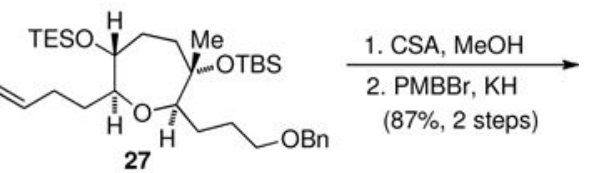

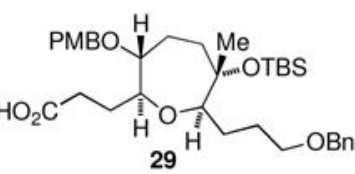

Scheme 6.

Synthesis of Brevenal's E-Ring Precursor 


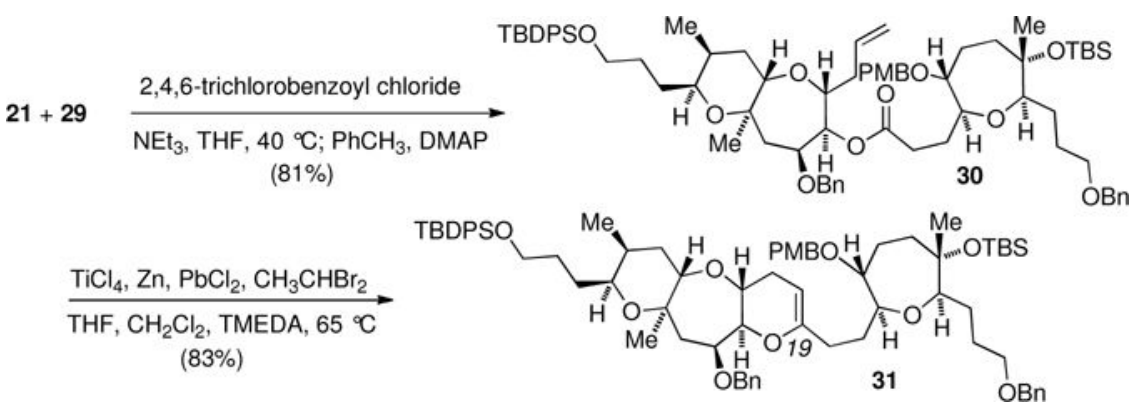

Scheme 7.

Coupling to Brevenal's C-Ring 

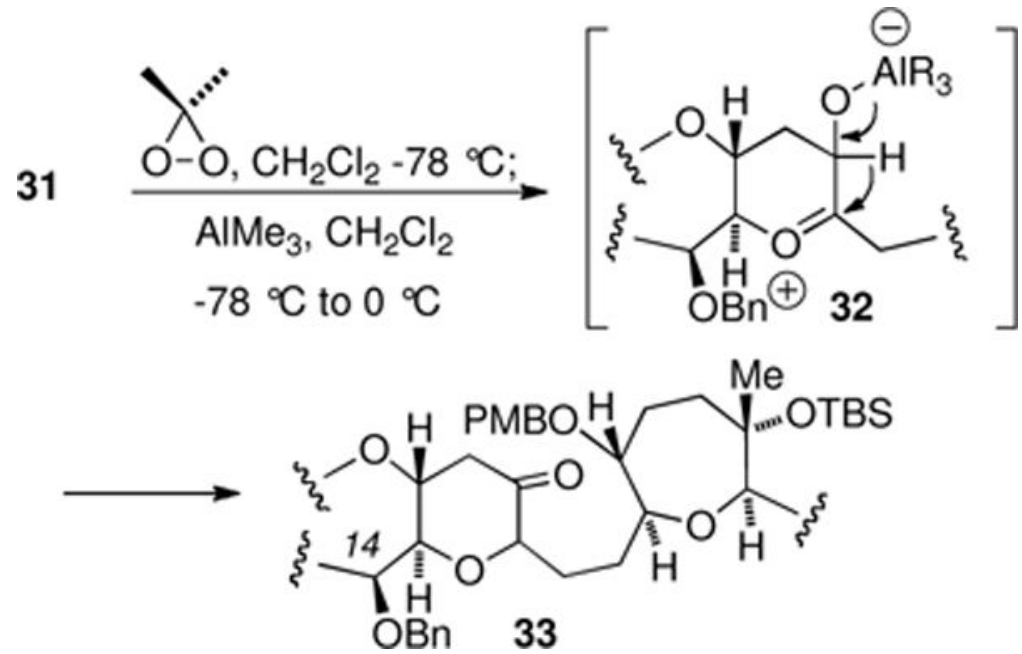

Scheme 8.

Pinacol-Type Rearrangement of 31 


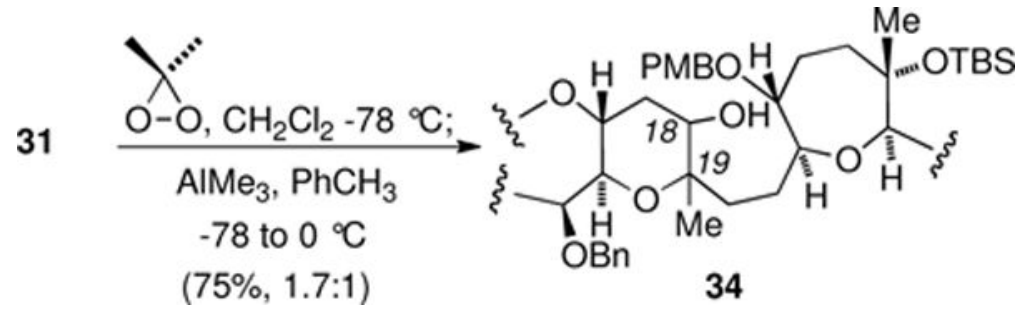

Scheme 9.

$\mathrm{Me}_{3} \mathrm{Al}$ Addition to 31 

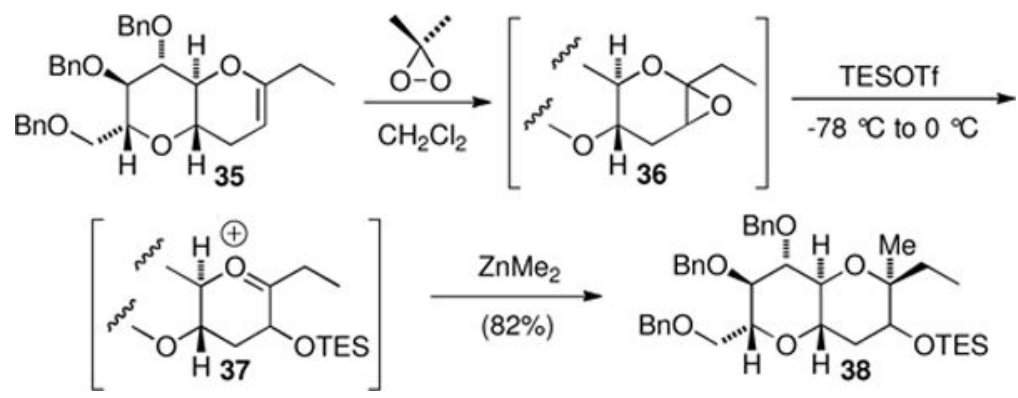

Scheme 10.

Oxocarbenium Ions from Glycal Epoxides 
31

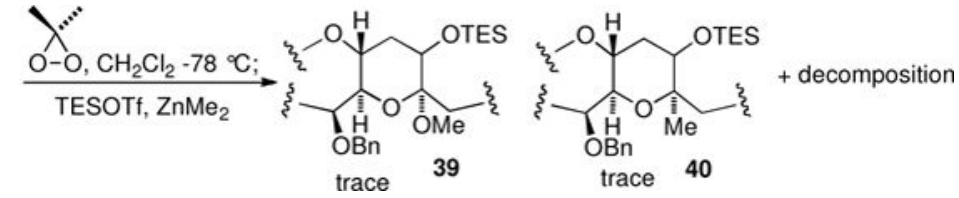

Scheme 11.

Attempted Generation of 40 
31
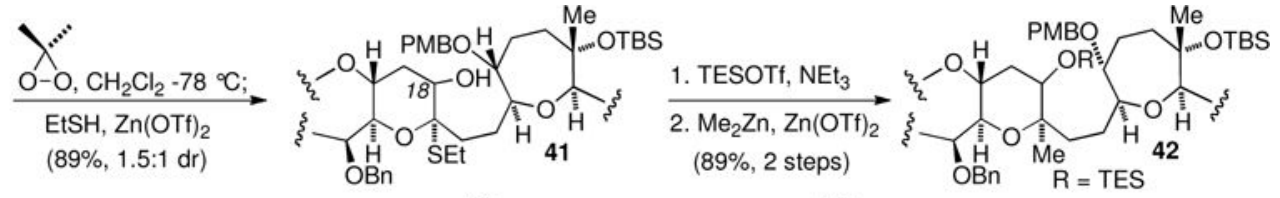

$$
\rightarrow
$$$$
\text { ( } 91 \%, 3 \text { steps) }
$$

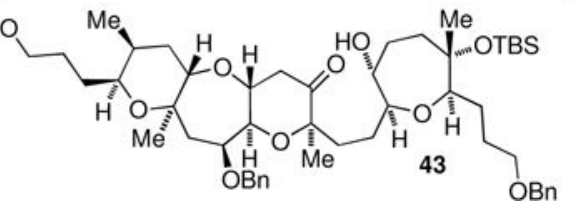

Scheme 12.

C(19) Methyl Incorporation 


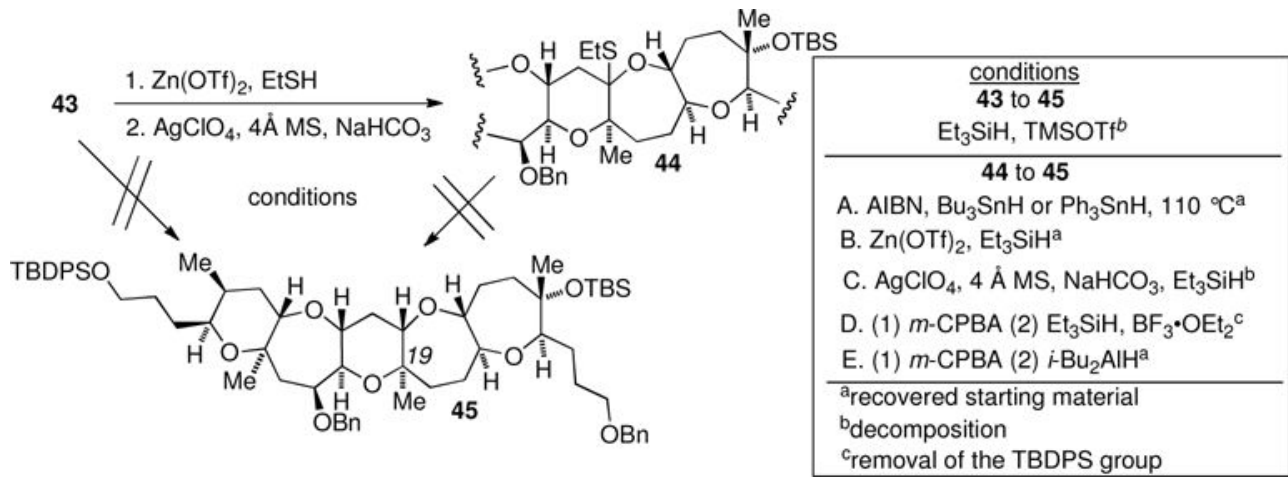

Scheme 13.

Attempts at Brevenal's D-Ring 


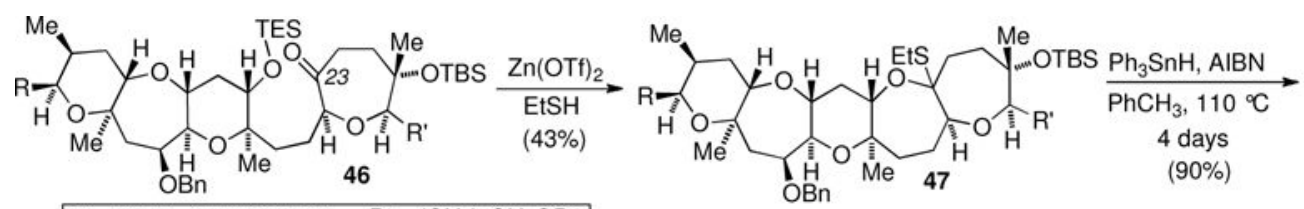
$\mathrm{R}=\left(\mathrm{CH}_{2}\right)_{2} \mathrm{CH}_{2} \mathrm{OTBDPS} \quad \mathrm{R}^{\prime}=\left(\mathrm{CH}_{2}\right)_{2} \mathrm{CH}_{2} \mathrm{OBn}$

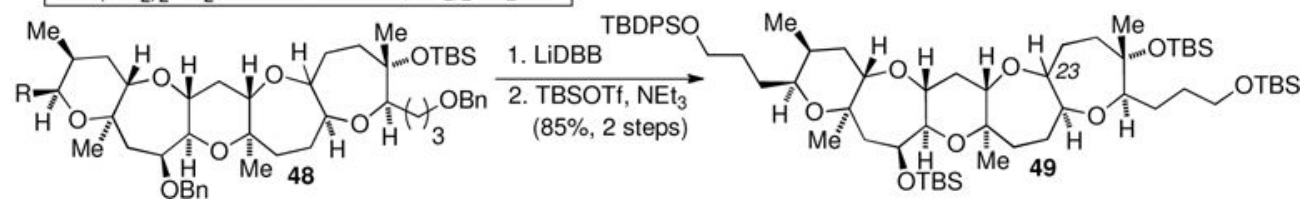

Scheme 14.

C(23)-Epi-Brevenal Core 

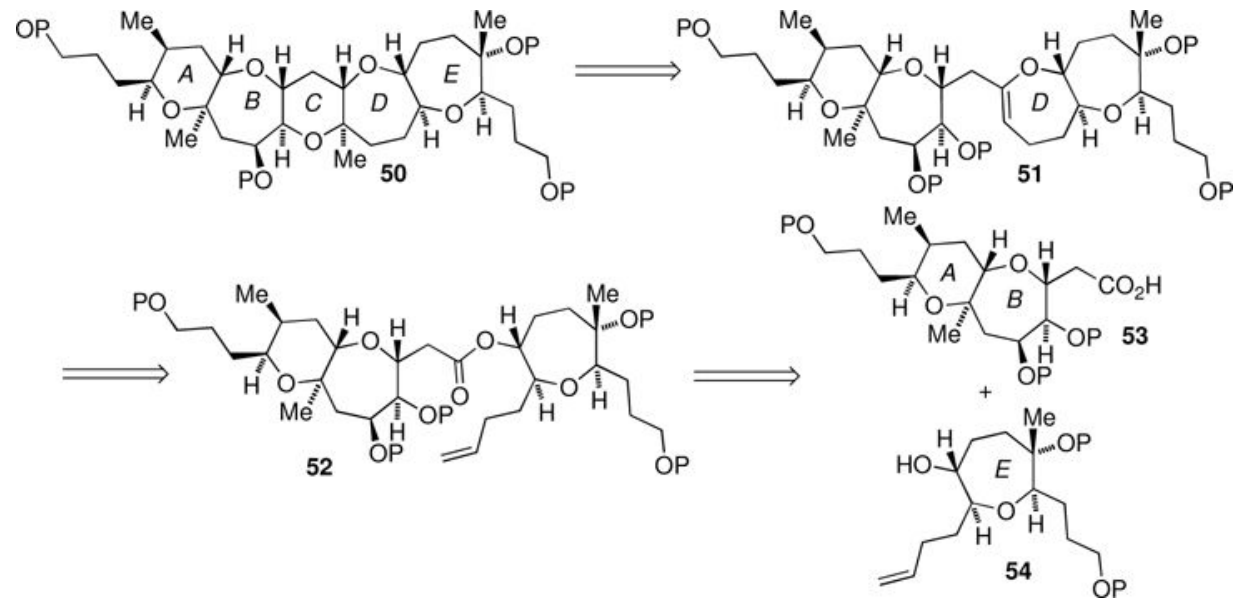

Scheme 15.

Brevenal Retrosynthesis-2 

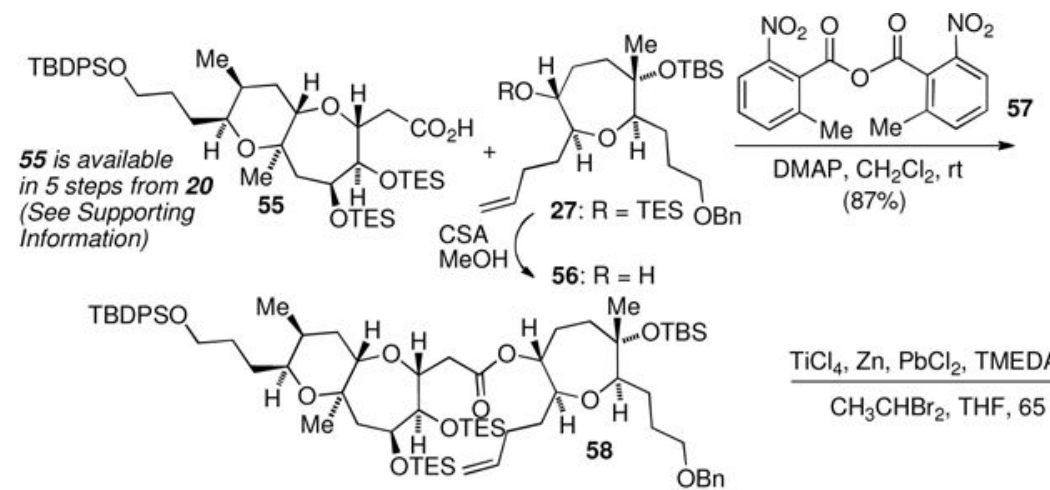

$\frac{\mathrm{TiCl}_{4}, \mathrm{Zn}, \mathrm{PbCl}_{2}, \text { TMEDA }}{\mathrm{CH}_{3} \mathrm{CHBr}_{2}, \mathrm{THF}, 65^{\circ} \mathrm{C}}$
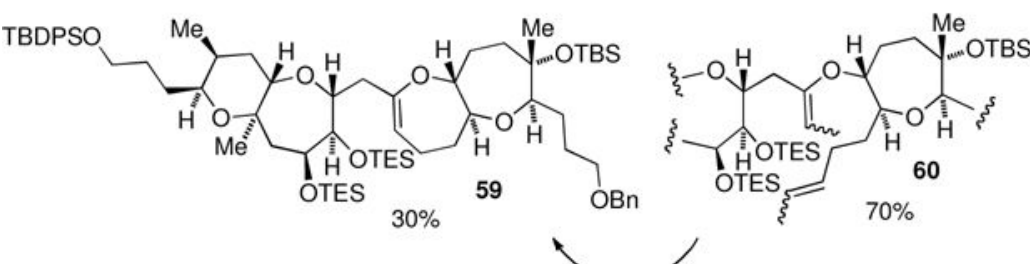

13, $\mathrm{CH}_{2}=\mathrm{CH}_{2}, \mathrm{PhH}, 80{ }^{\circ} \mathrm{C}$ ( $60 \%$ (5:1 oxepene:dihydropyran), $65 \%$ overall yield)

Scheme 16.

Subunit Coupling Part 2 

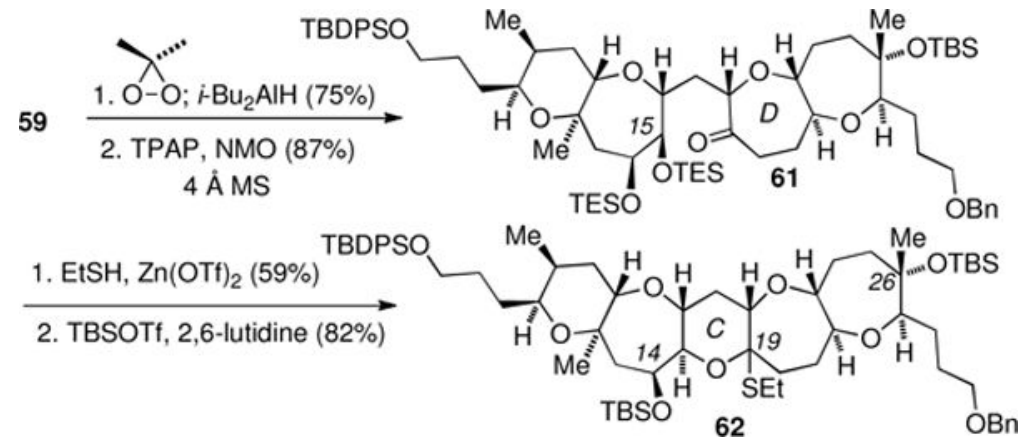

Scheme 17.

Completion of the D-ring and Thioketal Formation 
62

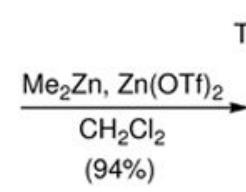

TBDPSO

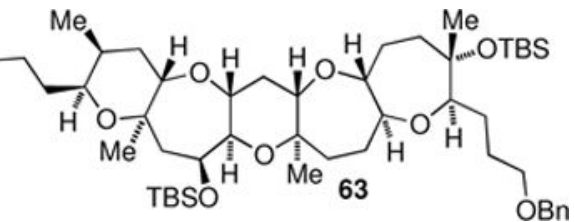

Scheme 18.

Brevenal's Pentacyclic Core 


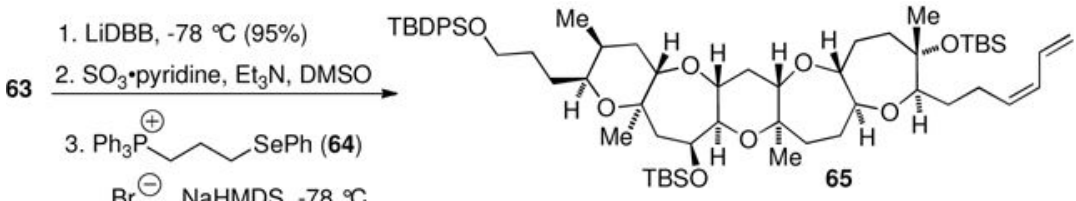

$\mathrm{Br}^{\ominus}$ NaHMDS, $-78^{\circ} \mathrm{C}$

4. $\mathrm{H}_{2} \mathrm{O}_{2}, \mathrm{NaHCO}_{3}, 30^{\circ} \mathrm{C}$ ( $87 \%, 3$ steps)

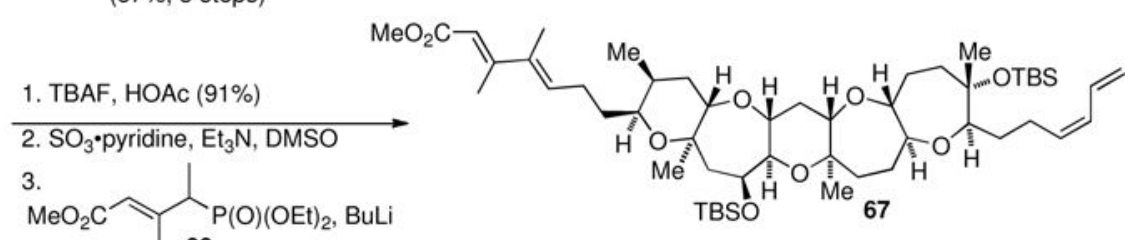

3.

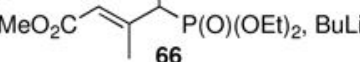

(85\%, 2 steps)

1. HF•pyridine

2. $i-\mathrm{Bu}_{2} \mathrm{AlH},-78^{\circ} \mathrm{C}$

3. $\mathrm{MnO}_{2}$

( $80 \%, 3$ steps)

Scheme 19.

Brevenal-Completion 